\title{
Going Back To Understand the Future: Socioeconomic Position and Survival after Myocardial Infarction
}

D. o we really need another paper on socioeconomic inequalities in health? After all, we have known for decades (or centuries, as some would say [1]) that, for most health outcomes, the rich do better and the poor do worse (2). After a literature search (3), I found that the rate at which articles were being published on this topic was more than 300 papers per month. When I recently updated the search, the exponential increase in publications had not abated in the slightest. We hear whispers of "enough studies, it's time to intervene," and yet more and more submissions arrive on the desks of journal editors and reviewers.

Current research on socioeconomic disparities in health can be grouped into 3 main areas. First, many studies are further documenting the association between socioeconomic position and health. Second, numerous studies seek the reasons for the association. Within this domain, some offer explanations that invoke poverty and material conditions on the one hand and psychosocial factors, such as control or depression, on the other (4); others examine the role of behavioral and biological pathways that link socioeconomic position and health (5). Other studies that fall into this category have investigated the causes of socioeconomic inequalities throughout the course of life, perhaps even starting in utero (6); the contribution of neighborhoods and communities to disparities (7); and, of course, the role of access and quality of medical care (8). Third, other studies have examined interventions to reduce income-related disparities in health outcomes; this category has far fewer examples.

In this issue, Alter and colleagues (9) seek explanations by using data from a cohort of almost 5000 Canadian patients who were hospitalized after myocardial infarction (MI). The researchers examined the association between income and 2-year survival after MI. They focused on how demographic factors, disease history, current risk factors, aspects of care, and psychosocial factors contributed to the higher mortality rate in patients with low household incomes $(<\$ 30000$ Canadian) compared with those who had high incomes ( $\geq \$ 60000$ Canadian). They obtained patient data (except for smoking and family history) from hospital discharge records, which is a better source than the patient's recollection or someone's assessment of the patient's clinical status at the time of the MI. For every patient, they had information regarding cardiovascular disease and risk factors for as many as 12 years before the index MI.

Alter and colleagues, like others before them, found relationships between socioeconomic position and both the incidence of vascular disease and patient survival with vascular disease (10). Of note, they found that the association between household income and mortality rate was substan-

www.annals.org tially weaker after they adjusted for differences in the between-group prevalence of preexisting cardiovascular disease and cardiac risk factors (diabetes, hypertension, hyperlipidemia, smoking, and family history of cardiovascular disease). Although these observations advance the field, they are not surprising. The strongest predictor of outcome after MI is probably the patient's disease status before the index event. In fact, the subgroup analyses detailed in Alter and colleagues' Table 4 indicate that patients with higher household incomes had an increased survival rate only if they had a history of angina, previous MI, revascularization, or congestive heart failure. This subgroup finding seems to support the authors' argument that the association between socioeconomic status and survival after MI mainly reflects that poorer patients have a greater incidence of preexisting cardiovascular disease and atherogenic risk factors, both of which could decrease survival after MI.

How should we interpret the important role of preevent health status in explaining worse survival rates among poorer patients? This editorial considers 4 central issues: the interpretation of the words "cause" and "explain"; the role of disease determinants and processes that occur over the course of life in generation of socioeconomic inequalities in health; the importance of comprehensive, valid measures; and between-country variations in socioeconomic disparities.

Alter and colleagues "affirm the importance of traditional atherogenic risk factors as a major cause [emphasis added] of disparities between income and mortality rates." They propose that efforts to target cardiovascular risk factors among disadvantaged patients might reduce incomerelated disparities in outcome. But they also assert that previous health status and cardiovascular risk factors form the "central intermediary pathway" between socioeconomic position and survival after MI. If previous health status and atherogenic risk factors are on the pathway that connects socioeconomic level with disparities in clinical outcomes, are income-related differences in preevent cardiovascular health status also a "cause" of the disparities? Certainly, the relationship is causal because cardiovascular disease status before MI drives postinfarction survival. But what about the factors that Geoffrey Rose calls the "causes of the causes" (11)? As in much of the work in this area, the paper does not carefully distinguish between how socioeconomic position relates to outcomes - an issue of the intermediate mechanisms - and why income level is related to the intermediate mechanisms that drive outcomes (11). The answer to the "why" question requires an understanding of the social forces that lead to observed differences in disease and disease risk factors between people of different 
socioeconomic standing (12). In other words, even if we can identify all the intermediate mechanisms that explain the association, we still need to also understand why these mechanisms are distributed differently among the rich and poor. Presumably, the authors' goal of reducing vascular risk factors among the disadvantaged can only be achieved with an understanding of the intermediate pathways and the social forces that cause these intermediate factors to be differently distributed in the rich and the poor.

The importance of preevent health status in correlating socioeconomic position with survival after MI is also interesting from the perspective of disease progression. Atherosclerotic vascular disease develops over many decades, and the large window on disease status that the authors provide (as many as 12 years' worth of data) gives much more information about accumulative disease processes related to socioeconomic position than if they had only measured disease severity at time of hospital discharge. It would have been nice to know if poorer patients had a longer history of cardiovascular disease or cardiac risk factors.

Alter and colleagues also took on the shibboleths of the effects of psychosocial factors (marital status and social support) and medical care (quality of clinical care) on outcomes. They examined how each contributes to explaining the association between income and survival after MI. Neither of these influences accounted for income-related differences in survival. Here, I am less convinced by their findings because of the limitations in their choice of measures of psychosocial status and medical care quality. For example, they used 2 items (whether the patients lived alone and whether they had someone they could talk to about personal matters) to measure social contacts and social engagement. These questions do not adequately measure the breadth of psychosocial factors that other studies have found to be associated with cardiovascular outcomes. Even if they used high-quality measures, they evaluated too few variables to completely reject a role of psychosocial factors. Another example: They used the attending physician's specialty as a proxy for the quality of in-hospital pharmacologic management and the number of early revascularization procedures as a measure of quality of care. Without information on the severity of the MI and the clinical status of the patient, it is impossible to judge if revascularization was good care or unnecessary care. Because of these doubtful choices of measurement tools, we cannot say whether psychosocial factors and variations in medical care contributed to socioeconomic variations in the sample's survival rate after MI.

Finally, there is the issue of location. Alter and colleagues analyzed data from patients in Canada. Although Canada and the United States share a common border, their citizens do not share common health destinies. For example, if U.S. citizens died at the same rate as Canadians, the United States would have had 11\% fewer deaths than Canada in 1998, and most of these would have been from diseases related to the heart and circulation (13). Of even more importance, the relationship between income inequality and health outcomes is different in the 2 countries. The effects are weaker in Canada $(14,15)$, and we do not know why. Perhaps the links between income and the more proximal determinants of health outcomes are weaker in Canada. Perhaps universal access to health care in Canada partially shields the poor from the health consequences of poverty. The time seems ripe to compare the United States with Canada directly; a good starting point would be to replicate Alter and colleagues' study in the United States.

So, do we really need another paper on socioeconomic inequalities in health? This latest study has added to our knowledge, but can we assume that we can reduce socioeconomic inequalities in survival rates after MI simply by reducing levels of preexisting cardiovascular disease and atherogenic risk factors? To accomplish this goal, we must integrate our knowledge of upstream social determinants that lead to differential burdens of cardiovascular disease and its risk factors and the downstream, proximal biological factors that drive health outcomes (15). Building a bridge between these 2 bodies of knowledge could provide a way to decrease socioeconomic inequalities in survival.

George A. Kaplan, PhD

University of Michigan School of Public Health and Center for

Social Epidemiology and Population Health

Ann Arbor, MI 48104

Grant Support: By Robert Wood Johnson Foundation Health and Society Scholars Program and National Institute of Child Health and Human Development (R24 HD047861).

Potential Financial Conflicts of Interest: None disclosed.

Requests for Single Reprints: George A. Kaplan, PhD, Department of Epidemiology, University of Michigan School of Public Health and Center for Social Epidemiology and Population Health, 1214 S. University Avenue, Ann Arbor, MI 48104; e-mail, gkaplan@umich.edu.

Ann Intern Med. 2006;144:137-139.

\section{References}

1. Antonovsky A. Social class, life expectancy and overall mortality. Milbank Mem Fund Q. 1967;45:31-73. [PMID: 6034566]

2. Kaplan GA, Haan MN, Syme SL, Minkler M, Winkleby M. Socioeconomic status and health. In: Amler RW, Dull HB, eds. Closing the Gap: The Burden of Unnecessary Illness. New York: Oxford Univ Pr; 1987:125-9.

3. Kaplan GA, Lynch JW. Whither studies on the socioeconomic foundations of population health? [Editorial] Am J Public Health. 1997;87:1409-11. [PMID: 9314787]

4. Lynch JW, Smith GD, Kaplan GA, House JS. Income inequality and mortality: importance to health of individual income, psychosocial environment, or material conditions. BMJ. 2000;320:1200-4. [PMID: 10784551]

5. Bruner E, Marmot M. Social organization, stress, and health. In: Marmot M, Wilkinson RG, eds. Social Determinants of Health. 2nd ed. Oxford: Oxford Univ Pr; 2005:6-30.

6. Davey Smith G. Health Inequalities: Lifecourse Approaches. Bristol: Policy Pr; 2003. 
7. Kaplan GA. People and places: contrasting perspectives on the association between social class and health. Int J Health Serv. 1996;26:507-19. [PMID: 8840199]

8. Fiscella K, Franks P, Gold MR, Clancy CM. Inequality in quality: addressing socioeconomic, racial, and ethnic disparities in health care. JAMA. 2000;283: 2579-84. [PMID: 10815125]

9. Alter DA, Chong A, Austin PC, Mustard C, Iron K, Williams JI, et al. Socioeconomic status and mortality after myocardial infarction. Ann Intern Med. 2006;144:82-93.

10. Williams RB, Barefoot JC, Califf RM, Haney TL, Saunders WB, Pryor $\mathrm{DB}$, et al. Prognostic importance of social and economic resources among medically treated patients with angiographically documented coronary artery disease. JAMA. 1992;267:520-4. [PMID: 1729574]
11. Rose G. The Strategy of Preventive Medicine. Oxford: Oxford Univ Pr; 1992.

12. Lynch JW, Kaplan GA. Socioeconomic position. In: Berkman LF, Kawachi I, eds. Social Epidemiology. New York: Oxford Univ Pr; 2000:13-35.

13. Torrey BB, Haub C. A comparison of US and Canadian mortality in 1998. Popul Dev Rev. 2004;30:519-32.

14. Gorey KM, Holowary EJ, Fehringer G, Laukkanen E, Moskowitz A, Webster DJ, et al. An international comparison of cancer survival: Toronto, Ontario, and Detroit, Michigan, metropolitan areas. Am J Public Health. 1997;87:115663. [PMID: 9240106]

15. Ross N, Wolfson M, Kaplan GA, Dunn JR, Lynch JW, Sanmartin C. Income inequality as a determinant of health. In: Heymann J, Hertzman C, Barer ML, Evans RG, eds. Healthier Societies: From Analysis to Action. New York: Oxford Univ Pr; 2006:202-36.

\section{Policy ON TRIALS}

Annals will publish clinical trials only if they are registered in a public registry. Trials that begin on or after 1 July 2005 must be registered at or before the onset of patient enrollment. Registration of trials that began before 1 July 2005 may be done after onset of patient enrollment. Authors can obtain current information on acceptable registries at www.ICMJE.org and can register their trials free of charge at www .clinicaltrials.gov. 